\title{
Desafios da avaliação em saúde no SUS na percepção dos trabalhadores do estado do Acre
}

\author{
I ${ }^{1}$ Luci Maria Teston, ${ }^{2}$ Áquilas Mendes, ${ }^{3}$ Leonardo Carnut, ${ }^{4}$ Marilia Louvison I
}

Resumo: A avaliação permeia o campo da Saúde Pública. Ela torna possível obter informaçóes destinadas à construção de julgamentos capazes de serem traduzidos em ações relacionadas não apenas à melhoria das políticas públicas, mas também ao auxílio de grupos sociais na compreensão e na modificaçáo de seus problemas. Este artigo tem por objetivo conhecer as percepçóes de trabalhadores do SUS sobre o processo de avaliação em saúde realizado no Acre e, a partir destas percepçóes, refletir sobre os limites e os desafios de se fazer a avaliação em saúde no estado. Para isto, foram realizadas 26 entrevistas semiestruturadas com trabalhadores do SUS, bem como com usuário e gestor integrantes do Conselho Estadual de Saúde. Os depoimentos foram submetidos à técnica de análise de conteúdo. A avaliação em saúde é percebida como um poderoso instrumento de gestão, embora pouco utilizado no cotidiano dos gestores. Problemas relacionados à articulação, ao planejamento e à gestáo contribuem para um processo de avaliaçáo considerado incipiente e cartorial. A avaliação qualitativa, a intersetorialidade, a cultura avaliativa e o controle social são alguns dos desafios apontados. Há a necessidade da avaliação em saúde se constituir em prática social, não se limitando ao cumprimento de regras e de normas.

> Palavras-chave: Sistema Único de Saúde; política de saúde; avaliação em saúde; pessoal de saúde.

\author{
1 Universidade Federal do Acre. \\ Rio Branco-AC, Brasil (luci_ \\ teston@hotmail.com). \\ ORCID: 0000-0002-9565-6162 \\ 2 Universidade de São Paulo. São \\ Paulo-SP, Brasil (aquilasmendes@ \\ gmail.com). \\ ORCID: 0000-0002-5632-4333 \\ ${ }^{3}$ Universidade Federal de São \\ Paulo. São Paulo-SP, Brasil \\ (leonardo.carnut@gmail.com). \\ ORCID: 0000-0001-6415-6977 \\ ${ }^{4}$ Universidade de São Paulo. \\ São Paulo-SP, Brasil (mariliacpl@ \\ gmail.com). \\ ORCID: 0000-0003-1630-3463
}

Recebido em: 27/04/2020 Aprovado em: 15/10/2020 Revisado em: 29/03/2021 


\section{Introdução}

A avaliação está presente desde o princípio da história, mas somente após a Segunda Guerra Mundial o conceito de avaliação de políticas e programas no setor público emergiu. Isto se deve, em grande parte, à necessidade de os pesquisadores comprovarem o sucesso ou malogro dos programas implantados na intenção de verificar os atributos de eficácia, eficiência e efetividade no uso de recursos pelo Estado.

O crescente interesse no estudo da avaliaçáo por parte de especialistas demonstra o desafio de utilizá-la de forma efetiva para promover as mudanças necessárias e para o auxílio na prática cotidiana relacionada à saúde. A relevância da temática tende a estar atrelada à crise no setor, com a consequente busca por reflexóes sobre os resultados alcançados no sentido da melhoria do desempenho do sistema de saúde, bem como à crescente procura por transparência na gestão dos recursos públicos (FELISBERTO et al., 2017; ALMEIDA; TANAKA, 2016). No Brasil, a partir da década de 1980 a avaliação de políticas começou a se desenvolver, expressando-se do ponto de vista acadêmico e incorporando-se, em alguma medida, à rotina da administração pública (GOMES; BEZERRA, 2014).

Ao analisarem a expansão do interesse pela temática da avaliação em saúde no Brasil nos últimos anos, Furtado et al. (2018) enfatizam que o advento da avaliação no âmbito da política, planejamento e gestão da saúde ocorre a partir da incorporação do pensamento donabediano, no fim da década de 1980. Ou seja, predominam enfoques com origem do clássico escopo funcionalista donabediano de avaliação normativa (estrutura, processo e resultados), originalmente aplicada à avaliação da qualidade de cuidados em serviços de saúde. Atualmente, no entanto, os sistemas de saúde indicam a importância de uma avaliação mais contextualizada, voltada ao cotidiano dos serviços e, para além do próprio planejamento em saúde da década de 1980, reconhecida como um importante instrumento de formulação de políticas e de poder (TANAKA, 2017).

Mesmo sendo uma atividade antiga, conceituar avaliação não é uma tarefa fácil. Em seus estudos, Pinheiro e Silva Junior (2011) observam que a avaliação carece de uma definição única. Devido à natureza híbrida de seus objetivos, tende a reproduzir uma diversidade de maneiras de delimitá-los e analisá-los. Desta forma, torna-se um desafio propor a utilização de uma única definição para as práticas avaliativas. 
Em virtude de sua polissemia, parece pertinente focar mais na utilidade da avaliação do que em uma única conceituação conforme destacado por Cruz (2015). No que se refere à sua utilidade, os resultados têm alçado a centralidade da discussão ultimamente, forçando-se o processo de construção do modelo avaliativo para este fim. Não obstante, a avaliação dos processos, das decisôes, dos parâmetros e das mudanças alcançadas têm sido colocadas em segundo plano.

Ao discutir a filosofia da avaliação, Martuccelli (2015) propõe uma análise crítica em relação aos seus princípios, os quais convergem, segundo o autor, para o entendimento de que não há eficiência e progresso sem a avaliação. Em uma de suas críticas, destaca que nem todas as práticas avaliativas são suscetíveis de mensuração com a mesma confiabilidade, não somente por questôes técnicas, mas também por questôes relacionadas à natureza intrínseca das atividades. Neste sentido, as práticas avaliativas atuais têm suscitado os seguintes questionamentos: a avaliação servirá para quem? Como será utilizada? Como foi construída e implementada?

Essas perguntas desfrutam de especial valor quando se trata do ato de avaliar a implementação de políticas públicas que tem como fim concretizar direitos sociais. Isto porque, a partir da intencionalidade do governo da ocasiáo, os resultados da avaliação podem justificar desinvestimentos e/ou cortes sem que se considerem os aspectos metodológicos e a coerência com o exercício ampliado desses direitos. Este tem sido o caso da avaliação no setor saúde, especialmente no exercício do direito à saúde enquanto direito social conforme operacionalizado pelo Sistema Único de Saúde (SUS).

Assim, a avaliação no campo da Saúde Pública é dotada de certa especificidade no que tange à natureza da saúde enquanto direito social e, também, a lógica interfederativa que compóe esse sistema de saúde. Não por acaso, a Lei Orgânica do SUS (Lei no 8.080/1990) prevê que a União, os estados, o Distrito Federal e os municípios exerçam, entre outras atribuiçôes em seu âmbito administrativo, a definição das instâncias e mecanismos de controle, de avaliação e de fiscalização das ações e serviços de saúde, o que demonstra, já nesta primeira legislação, a complexidade envolvida no ato de avaliar este sistema.

Ao considerar esta complexidade, adere-se ao fato das regionalidades do Brasil enquanto país de proporçôes continentais. Isto exige uma adaptação dos modos de fazer a avaliação às necessidades locais, a ponto de, caso isto não seja respeitado, invalidar todo seu conteúdo. Este é o caso, por exemplo, do estado do Acre no qual, 
segundo o Plano Estadual de Saúde (2012-2015), 94,5\% da população é dependente do SUS (ACRE, 2012), tornando a decisão tomada sobre o resultado da política de saúde uma fortaleza ou uma ameaça à sobrevivência da sua população. Isto reforça a necessidade de estudos relacionados ao processo de avaliação em saúde realizado em um estado táo peculiar.

É nesse sentido que absolutizar o uso da avaliação enquanto ferramenta de gestão deve ser evitado, já que, a depender do caso, ela apresentará limitações e desafios. Para isto, torna-se essencial compreender como os trabalhadores do SUS, responsáveis por materializarem o processo de trabalho (ao realizarem açóes voltadas para a promoçáo, a proteçáo, a recuperação e a reabilitação) percebem o processo atual de avaliação.

Dessa forma, este estudo tem por objetivo conhecer as percepçôes de trabalhadores do SUS sobre o processo de avaliação em saúde realizado no estado do Acre e, a partir dessas percepçóes, refletir sobre seus limites e desafios em face à especificidade desta região.

\section{Percurso metodológico}

Trata-se de estudo de abordagem qualitativa, realizado por meio de entrevistas semiestruturadas aplicadas aos trabalhadores do SUS no âmbito do estado do Acre. A definição dos critérios de seleção dos sujeitos que formam o universo da pesquisa é elemento de suma importância nas entrevistas, visto que esta seleção produz efeitos na qualidade das informaçôes (DUARTE, 2002). Dessa forma, o número de sujeitos que participaram não foi determinado $a$ priori.

Foram realizadas 26 entrevistas semiestruturadas com trabalhadores do SUS entre novembro de 2015 a fevereiro de 2016. As entrevistas foram realizadas em Rio Branco e em Cruzeiro do Sul. A capital Rio Branco, com 46\% da população do estado, concentra a maior parte da infraestrutura administrativa estadual e dos serviços de saúde oferecidos (ACRE, 2016). Cruzeiro do Sul é o segundo município mais populoso do Acre, distante cerca de $600 \mathrm{~km}$ da capital.

Para a seleção foram adotadas duas estratégias: 1) 10 sujeitos foram mapeados por meio de amostra intencional considerando as áreas de atuação, assim definidas: a) gerentes de redes temáticas; b) conselheiros do Conselho Estadual de Saúde; c) membros da Comissão Intergestores Bipartite (CIB); e d) coordenadores estaduais 
das regionais de saúde; ${ }^{1}$ 2) foram identificados 16 informantes-chave por meio da técnica do snowball sampling ("amostragem em bola de neve"), que acompanhavam o processo de regionalização neste estado (ATKINSON; FLINT, 2001). Essa técnica consiste na escolha de um grupo inicial de sujeitos que preenchem os pré-requisitos da pesquisa, sendo que, após serem entrevistados, indicam novos sujeitos com as mesmas características para poderem contribuir para a pesquisa. $\mathrm{O}$ processo é repetido sucessivamente até que se tenha atingido o objetivo proposto. Participaram das entrevistas profissionais das áreas da Enfermagem (6), Assistência Social (3), Odontologia (3), Economia (2), Psicologia (2), Medicina (1), Nutrição (1), Farmácia (1), Pedagogia (1), Letras (1), Geografia (1), Biologia (1), Veterinária (1), Teologia (1) e de Ensino Médio (1).

Para além dos trabalhadores do SUS entrevistados, cabe ressaltar a participação de um usuário e de um gestor, ambos membros do Conselho Estadual de Saúde. Reconhece-se que o usuário não é trabalhador do SUS, porém integra a categoria dos envolvidos no sistema.

O processo de trabalho de campo foi finalizado quando se avaliou não haver mais dados originais ou elementos que trouxessem novas perspectivas à investigação, ou seja, quando as recorrências atingiram o chamado "ponto de saturação", em consonância com as orientações de Duarte (2002).

Um roteiro semiestruturado orientou a dinâmica das entrevistas, a partir de temas envolvendo: a) instrumentos de avaliação em saúde; b) articulação institucional; c) indicadores de saúde; d) desafios para a avaliação em saúde no SUS. Houve a apresentação do objetivo do estudo e a sua contribuição para o entendimento do processo de avaliaçáa em saúde no SUS, bem como foi informado aos sujeitos da pesquisa sobre a garantia do sigilo. A participação na pesquisa pressupôs a sua compreensão e a livre escolha em participar, o que foi comprovado pela assinatura do Termo de Consentimento Livre e Esclarecido (TCLE).

O material obtido foi transcrito manualmente na íntegra. Para a análise dos dados, foi aplicada a técnica de análise de conteúdo proposta por Bardin (2011). Iniciou-se pelo que a autora apresenta como "leitura flutuante" para, em seguida, serem identificadas as unidades temáticas presentes nas falas dos sujeitos da pesquisa e, posteriormente, procedeu-se à construção de categorias e subcategorias de análise, cada vez mais específicas e precisas em relação ao objeto da pesquisa e em torno das quais foram organizadas as falas dos sujeitos. A interpretação das informações obtidas 
foi realizada a partir da composição dessa estrutura. Para fins de análise, identificaramse os sujeitos por E1,E2, E3 e assim por diante, assegurando o anonimato.

$\mathrm{O}$ estudo faz parte de pesquisa de doutorado e foi desenvolvido considerando as diretrizes e normas estabelecidas para pesquisas com seres humanos contidas na Resolução no 466/2012, do Conselho Nacional de Saúde. O projeto foi aprovado pelo Comitê de Ética em Pesquisa da Faculdade de Saúde Pública da Universidade de São Paulo (Parecer n. 1.368.889).

\section{Resultados e Discussão}

Da análise às falas dos trabalhadores do SUS emergiram duas unidades temáticas: a) Atual processo de avaliação em saúde e b) Desafios para a avaliação em saúde. Das unidades temáticas emergiram categorias e subcategorias (quadro 1).

Quadro 1. Unidades temáticas, categorias e subcategorias das percepçôes dos trabalhadores do SUS sobre a avaliação em saúde no Acre, 2016

\begin{tabular}{|c|c|c|}
\hline $\begin{array}{l}\text { Unidades } \\
\text { Temáticas }\end{array}$ & Categorias & Subcategorias \\
\hline 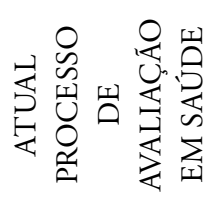 & $\begin{array}{l}\text { Avaliaçôes pontuais, } \\
\text { incipientes e cartoriais }\end{array}$ & $\begin{array}{l}\text { - Processo burocrático e normativo; } \\
\text { - Centralidade das avaliações quantitativas; } \\
\text { - Lógica assistencial hospitalar e especializada; } \\
\text { - Precarização das relaçôes de trabalho; } \\
\text { - Gestão pouco solidária e cooperativa. }\end{array}$ \\
\hline 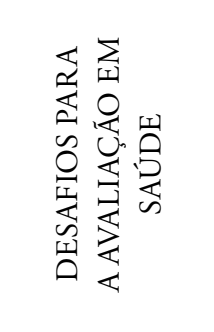 & $\begin{array}{l}\text { Institucionalização da } \\
\text { avaliação }\end{array}$ & $\begin{array}{l}\text { - Articulação entre os instrumentos de planejamento } \\
\text { e de gestáo; } \\
\text { - Avaliações qualitativas e aproximaçáo do cotidiano } \\
\text { do SUS; } \\
\text { - Importância da atenção básica, da promoção da } \\
\text { saúde e da intersetorialidade; } \\
\text { - Fortalecimento do SUS e das regiões de saúde; } \\
\text { - Cultura avaliativa e controle social. }\end{array}$ \\
\hline
\end{tabular}

Fonte: elaboração própria.

\section{Atual processo de avaliação em saúde}

\section{Processo burocrático e normativo}

Para os participantes da pesquisa, o processo de avaliaçáo encontra-se situado em um campo normativo. Relatam serem poucas as situaçóes em que os processos 
avaliativos são percebidos como uma oportunidade para a gestão. As avaliaçóes são realizadas para o cumprimento de exigências formais e legais do Ministério da Saúde. Desta forma, são vistas como um instrumento obrigatório, ou seja, cartorial, e não como um elemento estruturante da política do SUS:

A questão de utilizar a avaliação como subsídio para correção de erros eu vejo que isso não existe. As avaliaçôes que são feitas são protocolares e são avaliaçôes que atendem principalmente a uma necessidade de prestação de contas documental (E11).

Outra afirmação recorrente nas falas dos entrevistados é a pouca comunicação entre a equipe técnica e o setor de planejamento da Secretaria Estadual de Saúde (Sesacre). Houve relatos sobre a necessidade de ser aperfeiçoado este processo no âmbito interno da Sesacre, mas também na relação do governo do Estado com os municípios e dos profissionais de saúde para com a população.

Um dos reflexos da falta de comunicação é a falta de planejamento. Há o argumento de que os processos avaliativos atuais constituem uma etapa burocrática do planejamento, e não enquanto ferramentas de redirecionamento das açóes ou de racionalização de recursos assistenciais e financeiros:

Percebe-se que na Sesacre não existe uma avaliação de desempenho permanente que possa sugerir e indicar melhorias ou reformulaçóes necessárias e possíveis, para assegurar o cumprimento dos objetivos da política de saúde (E20).

Para a elaboração do Plano Estadual de Saúde (2016-2019), além da utilização do marco legal, consta a utilizaçáo do Relatório Anual de Gestão (RAG) e do Plano de Governo 2012-2015 como referências. Somam-se a isso a VII Conferência Estadual de Saúde (2015) e as políticas prioritárias de governo (ACRE, 2012; 2016). Entretanto, predomina o entendimento, por parte dos sujeitos da pesquisa, da não relação entre os instrumentos de gestão de governo e os instrumentos de gestão da saúde, apesar de alguns entrevistados citarem certo empenho do governo em conectar estes instrumentos.

Existe um plano orçamentário que não conversa com os planos de saúde, podem até se encontrar nas frases e nas determinações cartoriais, mas na sua execução é uma guerra e uma tragédia (E17).

Há, segundo relatos, a preocupação dos instrumentos de planejamento e orçamento de governo ${ }^{2}$ e dos instrumentos de planejamento e orçamento da saúde pública $^{3}$ se coadunarem apenas "no papel”. Na prática, o processo de construção não é ascendente, ou seja, não parte das bases, ao desconsiderar o anseio e as 
necessidades dos usuários, refletindo de forma unilateral o pensamento e o planejamento dos gestores.

Esses instrumentos de planejamento e de orçamento, com o plano de governo, eles são feitos muito em nível de gabinetes, entáo quem está nas unidades, quem está na assistência tem muito pouco acesso a esses instrumentos [...]. (E2).

A avaliação externa à gestão sugere avaliações realizadas de forma isolada, ocasionais e, como consequência, com pouca interferência no processo de tomada de decisôes. Essa problemática traz a questão da institucionalização da avaliação enquanto um esforço no sentido de tornar a prática avaliativa parte integrante do processo decisório (GASPARINI; FURTADO, 2014).

\section{Centralidade das avaliaçóes quantitativas}

A centralidade das avaliaçôes quantitativas também é apontada como um dos problemas da avaliação em saúde incipiente e pontual realizada no estado do Acre. Como exemplo, sujeitos da pesquisa citaram o quadro atual de indicadores de saúde, os quais pouco estariam refletindo em termos de qualidade das açôes e dos serviços de saúde ofertados.

O processo atual de avaliação ainda é muito engessado e sem focar na avaliação qualitativa, com poucos indicadores que reflitam qualidade e não quantidade [...]. Acredito que os mecanismos de avaliação existentes ainda não dáo conta de avaliar a qualidade da atenção à saúde, pois estão muito focados na avaliação quantitativa (E7).

A forte influência positivista na avaliação em saúde alinha-se ao predomínio de métodos quantitativos de análise. Mesmo observando-se uma crescente incorporação de estudos qualitativos, as teorias e os métodos a que estes estudos são submetidos muitas vezes não escapam dessa influência positivista (PINHEIRO; SILVA JUNIOR, 2011; GOMES; BEZERRA, 2014). São estudos que ainda não preveem a adoção de critérios permeáveis às transformaçôes presentes no cotidiano dos atores em suas práticas nas instituições de saúde.

No contexto da influência positivista, cabe ressaltar o conceito de avaliaçóes econômicas citado por Roseboom et al. (2017). Em estudo com o objetivo de fornecer informaçôes sobre o uso atual e potencial de avaliaçôes econômicas na tomada de decisóes na área de saúde na Holanda, os autores demonstraram que o uso atual e o impacto das avaliaçóes econômicas são limitados, na melhor das hipóteses. Para eles, são necessárias estratégias para superar as barreiras que impedem que as avaliaçóes 
econômicas sejam amplamente utilizadas, pois entendem que o uso de avaliaçóes econômicas na tomada de decisóes em saúde pode potencialmente ajudar os tomadores de decisão na alocação de recursos escassos da maneira mais eficiente possível.

No entendimento de Furtado et al. (2018), a utilização da avaliação de forma instrumental tem gerado críticas. Os autores questionam a forma de indução de políticas geralmente focada em resultados e considerada conservadora, visto não haver apoio institucional e nem auxílio financeiro, técnico ou científico aos mais mal avaliados e com desempenho fora do padrão, no sentido de buscar atenuar ou mesmo superar problemas sociais. Esta forma de indução de políticas, entendem, é ideal no ponto de vista da racionalidade de mercado, mas mostra-se inconciliável com a lógica pública.

Para Martins (2011, p. 53), o principal problema das abordagens predominantemente quantitativas relaciona-se ao excesso de cuidado com a organização de conteúdos "aritmeticamente ordenados e determinísticos", o que termina "negligenciando justamente os elementos não-causais, dissipativos e mesmo caóticos que estão presentes em todos os planos da vida social”. O autor explica esse argumento a partir do entendimento de que a capacidade de organização do sistema de saúde não pode ser definida a priori nas planilhas de custos, nas leituras de dados estatísticos e na produção de cenários alternativos.

Há, dessa forma, a necessidade das avaliaçóes, na tentativa de se afastarem da perspectiva meramente cartorial, considerarem aspectos qualitativos. Nesse sentido, Martins e Bezerra (2014, p. 41) ilustram este argumento quando ressaltam que, na atenção primária, a avaliação em saúde não deve se restringir a indicadores quantitativos - os quais tendem a colaborar, quando analisados isoladamente, para a desorganização dos programas de atenção em saúde -, mas incorporar critérios e indicadores qualitativos "que explicitem a complexidade das relaçôes intersubjetivas".

Nesse contexto, Martuccelli (2015, p. 43-44) destaca que todo indicador, para além da perspectiva técnica, também é resultado de uma escolha política por omissão, visto que "ele desloca a decisão política no momento da construção anterior aos indicadores, mas não aumenta forçosamente a transparência”. Além disso, a "confecção de indicadores escamoteia o momento político atrás de um debate aparentemente técnico". Para o autor, se o objetivo é a transparência de poder, se faz necessária uma discussão aberta diante da opinião pública em relação aos indicadores escolhidos. 


\section{Lógica assistencial hospitalar e especializada}

Em depoimentos de entrevistados, observa-se que o foco das açóes de governo está relacionado aos serviços de média e alta complexidade:

Eu fico um pouco preocupada com os caminhos que eu tenho percebido, as prioridades, hoje a gente faz transplante, mas a gente não alcança meta de vacina e aí eu caio na discussão anterior, é necessário o transplante? É necessário, a gente não pode deixar de investir, mas eu acho que a gente precisaria, o Estado pelo menos precisaria focar mais na atenção básica mesmo (E5).

A atenção básica é vista como um elemento importante para o processo de avaliação em saúde. Desta forma, o estado do Acre investiria menos recursos se as açôes primárias estivessem acontecendo de forma adequada:

[...] um Estado com baixos índices de vacinaçáo, baixa de cobertura de PCCU, altos índices de internação por causas evitáveis deveria ampliar os investimentos da atenção básica, ao invés da atenção especializada (E8).

Conforme esclarece Mészáros (2012), é muito difícil se contrapor à inexorável força do capital e do seu aliado mais fiel, o Estado. Estes atuam no sentido de perpetuar o domínio do capital via dura imposição de conformidade ideológica e política. Há a busca da propagação de uma ideologia única, indispensável para a uniformidade do capital e, para isso, faz-se o uso de diversos meios, inclusive aqueles considerados violentos.

A ideologia atualmente propagada é a do consumo, principalmente de tecnologias pesadas, que não se alinha ao fortalecimento da atenção básica. Ou seja, é na média e na alta complexidade que o consumo, principalmente de medicamentos e serviços, contribui para uma saúde associada a uma lógica de mercado. Também é na média e na alta complexidade onde se consomem grande parte dos recursos destinados à saúde.

Para Gomes e Bezerra (2014, p. 16), o SUS é lugar onde ocorrem disputas entre diversos modelos de assistência à saúde, com a tendência de se manterem modelos hegemônicos, os quais compreendem um modelo assistencial privatista com foco na assistência médico-hospitalar e nos serviços de apoio diagnóstico e terapêutico, bem como o modelo sanitarista que enfatiza as açôes de vigilância epidemiológica e sanitária e as campanhas de combate às doenças. Entretanto, há esforços em paralelo no sentido de se construírem "modelos alternativos que contemplem a articulação das ações de promoção, prevenção e recuperação da saúde, nas dimensões individual e coletiva”. 


\section{Precarização das relaçóes de trabalho}

Outro fator importante para a incipiência no processo de avaliçáa em saúde decorre, segundo relatos, da precarizaçáo das relaçóes de trabalho. Citou-se que a Secretaria Estadual de Saúde procura realizar treinamentos constantes junto às secretarias municipais, tendo em vista a grande quantidade de sistemas utilizados no campo da saúde. Os profissionais recebem o treinamento, porém, não raro, acabam sendo substituídos por outras pessoas forçando, com isso, o retrabalho e reforçando as dificuldades.

Se você capacita um determinado profissional em determinada área, amanhã ele já saiu e chegou outro porque tem a questão da precariedade da relação de trabalho, às vezes a pessoa é terceirizada, é emprestada, cedida, é cargo comissionado, não tem um vínculo efetivo e tudo isso contribui negativamente para que a coisa não avance (E4).

Em referência aos anos 1970, Castel (2010) traz uma importante contribuição relacionada à insegurança frente às grandes transformaçóes contemporâneas. Para o autor, o advento do novo regime capitalista pós-industrial trouxe um processo de descoletivização ou de reindividualização. Há, a partir de então, processos relacionados à individualização de tarefas, ampliação de contratos temporários e terceirização em larga escala. Os antigos coletivos de trabalho náo funcionam e os trabalhadores passam a competir uns com os outros, o que traz efeitos profundamente desestruturantes sobre a solidariedade. As carreiras profissionais se tornam descontínuas e não mais se inserem nos regulamentos coletivos de emprego estável.

\section{Gestão pouco solidária e cooperativa}

Aliada à precarização das relaçôes de trabalho, encontra-se uma gestão pouco solidária e cooperativa. A fragilidade técnica das secretarias municipais e a dificuldade da secretaria estadual em coordenar processos estaria contribuindo para agravar esse cenário. Há o destaque para a fragmentação dos programas e desconsideração em relação à sua transversalidade, pelo fato de cada equipe atuar isoladamente junto aos municípios.

Isso seria reflexo de uma cadeia de eventos, resultado de programas já fragmentados no âmbito do Ministério da Saúde. Ou seja, é uma percepção baseada na verticalidade, onde cada um estaria fazendo a parte que lhe cabe. As visitas realizadas pela gestão estadual com o objetivo de apoiar os municípios acabam por se tornar visitas de cobrança decorrentes de resultados náo alcançados: 


\begin{abstract}
A Secretaria de Estado que tem a obrigação legal de estar acompanhando os municípios, que é uma das atribuiçóes da Secretaria de Estado [...], ela vai duas vezes por ano só para cobrar, ela deveria estar lá ajudando os municípios durante todo o período do ano, para a coisa não chegar tão ruim no final (E23).
\end{abstract}

Percebem-se dificuldades importantes no processo de articulação entre a Secretaria Estadual de Saúde e os municípios, transitando desde a formação de equipes mínimas, insuficientes para atender aos municípios em suas necessidades, refletindo um modelo no qual os municípios percebem mais a cobrança do que propriamente o apoio.

Para Almeida e Tanaka (2016), as iniciativas no campo da avaliação em saúde no âmbito do Ministério da Saúde são dirigidas para a atenção à saúde em nível federal, sem levar em consideraçáo a necessidade do ajuste dos programas aos diferentes contextos em que estão inseridos, o que estaria dificultando a tomada de decisão descentralizada. Nesse contexto, argumentam sobre a importância de a avaliação adquirir uma abordagem participativa e ser fonte primordial de informaçôes essenciais para a tomada de decisão em nível local, proporcionando a ampliação do potencial de mudanças nas práticas de trabalho de gestão no âmbito dos municípios.

Esses elementos, aliados às dificuldades financeiras na condução desses processos, tanto por parte do estado do Acre em mobilizar e garantir a logística das equipes que estariam realizando o apoio técnico aos municípios, quanto aos próprios municípios, que sentem a cobrança por não alcançarem as metas pactuadas, contribuem para reforçar a fragilidade do processo de avaliação em saúde.

\title{
Desafios para a avaliação em saúde
}

\section{Importância do planejamento e dos instrumentos de gestão}

Um dos grandes desafios atuais no campo da avaliação em saúde é sua institucionalização, o que significa incorporá-la e inseri-la nos processos de planejamento e de gestão (OLIVEIRA; REIS, 2016). Para uma avaliação adequada, os instrumentos de gestão devem estar alinhados. Esta é a compreensão dos sujeitos da pesquisa, os quais reforçam a ideia de que esse alinhamento trará à avaliação planos realistas que permitam criar estratégias adequadas e correspondentes à realidade da saúde:

Como eu descreveria o processo atual de avaliação em saúde? E digo que o processo hoje ele estaria em torno de $50 \%$ a $40 \%$ falho, falho, porque os instrumentos que deveriam ser 
utilizados para planejamento, acompanhamento, monitoramento e avaliação das ações eles não estão alinhados. Ou seja, nós temos primeiro que discutir os instrumentos, entendermos a importância dos instrumentos, criarmos condiçóes técnicas para que esses instrumentos sejam utilizados. Este é o grande desafio futuro (E10).

Nesse aspecto, importante contribuição é encontrada em Tamaki et al. (2012). Os autores, que desenvolveram uma metodologia de construção de um Painel de Monitoramento e Avaliação da Gestão do Sistema Único de Saúde, entendem como relevante o destaque dado aos aspectos normativos e legais estabelecidos no planejamento em saúde, como os planos de saúde, os relatórios de gestão, com atenção especial para o Pacto de Gestão e o Contrato Organizativo da Ação Pública da Saúde (COAP).

Nessa linha, Miranda, Carvalho e Cavalcante (2012) ressaltam a fragmentação no uso das informaçóes, as quais deveriam estar conexas e coesas. Entendem que há poucas conexóes entre o estabelecimento de direcionalidade e operacionalidade; além disso, demonstram preocupação em relação às referências relativas ao uso efetivo de instrumentos normativos de gestáo, como planos de saúde, planos orçamentários e relatórios de gestáo.

Em estudo de caso para analisar uma arquitetura de informaçóes em saúde em Bihar, terceiro estado mais populoso da Índia, Kumar, Mostafa e Ramaswamy (2018) propóem a adoção de um sistema federado, com potencial para fornecer flexibilidade para a inovação local; atender às diversas necessidades de informaçóes de provedores de assistência médica, gerentes de programas e formuladores de políticas; e incentivar a tomada de decisóes com base em dados. Segundo os autores, as informaçóes em saúde da Índia e de outros países em desenvolvimento, ao estarem organizadas com foco na coleta de dados quantitativos da população devido à proeminência de doenças infecciosas e transmissíveis, falham em fornecer informaçôes precisas e completas sobre saúde por estarem estruturadas de forma vertical e fragmentada. Esta fragmentação leva à ineficiência, à baixa qualidade dos dados, ao uso limitado de dados e negligência das necessidades de informaçóes dos prestadores de serviços de saúde.

Em Contandriopoulos et al. (1997), tem-se a ideia de uma avaliação útil. Os autores argumentam sobre a necessidade da conscientização de que a avaliação produza informação e, portanto, seja fonte de poder para aqueles que a controlam retirando a centralidade do resultado apenas e reestabelecendo a importância do 
processo como um todo. Para isto, entendem que devem ser assegurados, entre outros requisitos, que todos os envolvidos no processo de avaliação possam definir os problemas que devem ser revolvidos e as estratégias de pesquisa e que haja a consciência sobre o fato de que quem decide, muitas vezes, não tem condiçôes de definir de forma exata as necessidades de informações e, portanto, ter a compreensão de que a avaliação pode responder parcialmente a alguns dos problemas enfrentados.

\section{Avaliaçóes qualitativas e intersetorialidade}

Outro desafio proposto pelos sujeitos da pesquisa é o de concentrar esforços no sentido de uma avaliação qualitativa. Os entrevistados, em suas falas, destacaram ser fundamental que os gestores municipais e a gestão estadual desenvolvam estudos para além dos quantitativos no sentido de serem identificadas as potencialidades e as fragilidades da saúde pública, estimulando os gestores da saúde a elaborarem seus projetos direcionados às necessidades de saúde e à construção de uma rede de atenção. Neste sentido, um dos desafios é trabalhar a intersetorialidade.

Eu acho que a intersetorialidade é uma necessidade, acho que a questão de investimento em educação permanente é um desafio, porque a gente ainda não consegue perceber isso, a burocracia que está posta, quando a gente tenta executar uma ação, a gente planeja lindamente, calcula e a gente não consegue e você tem uma frustação muito grande (E5).

Para Pisco (2006, p. 567), a questão central do processo atual de avaliação não é tanto a técnica, ou seja, de como se fazem atividades de avaliação e melhoria. Os esforços devem se concentrar em como se estabelecer e se manter, de forma sustentada, essas atividades como parte do trabalho de um sistema de saúde. Nesta perspectiva, argumenta no sentido de se pensar a criação bem-sucedida de um sistema que, "de forma coerente e integrada, englobe os múltiplos esforços qualitativos que os profissionais ou as instituiçôes estão a desenvolver de forma a potenciar os benefícios para os doentes".

Assim, apenas em uma abordagem qualitativa é que a avaliação poderá apreender essa "fineza" do processo. Carnut (2020) ressalta que uma das agendas em que os estudos avaliativos devem se assentar nos próximos anos é o estudo e elaboração de instrumentos de avaliação com abordagem qualitativa, especialmente sobre o cotidiano dos serviços de saúde. Somado a isso, deve-se perseguir como esses recursos podem detectar as fragilidades das relaçóes de comunicaçáo entre serviços, ou seja, como identificam as lacunas na construção da intersetorialidade na vida concreta dos serviços. 
Incorporada de forma sistemática nos diversos níveis dos serviços de saúde, a avaliação traz aos gestores a oportunidade de terem acesso a informações necessárias para a definição de estratégias de intervenção. Coadunando com Silva e Formigli (1994), existe uma grande quantidade de informaçôes registradas pelos serviços que estão disponíveis, mas que acabam não sendo utilizadas, seja para a análise da saúde, seja para a definição de prioridades e para a reorientação de práticas. Entende-se que se tais informaçóes rotineiramente registradas fossem de fato analisadas, seriam matéria-prima para a construção de um necessário processo contínuo de avaliação dos serviços de saúde.

\section{Fortalecimento do SUS e da política de regionalização}

Entre os desafios no processo de incorporação da avaliação no cotidiano do setor da saúde, podem ser citados a falta de tradição em avaliar, bem como a pouca compreensão do que é o SUS por parte de muitos atores. Desta forma, a implementação de uma política de avaliação em saúde poderia fortalecer o próprio SUS no estado. Enxergá-lo como uma conquista da sociedade brasileira foi um dos desafios apontados pelos sujeitos da pesquisa. Há o entendimento de que está em curso um movimento político forte no sentido de fragilizar o modelo atual:

Então o que a gente vê é um movimento muito forte, político, forte, que quer toda a hora
derrubar o modelo assistencial do SUS, porque não é atrativo, é gasto [...]. E é tão invejado
pelos outros países, mas, ao mesmo tempo, o próprio país desconhece dele, do modelo
que nós temos, porque existe ainda o modelo da velha política atuando em fortes decisóes
[...], aí a coisa cada vez mais vai se esfacelando. Hoje eu vejo o SUS tipo como uma criança
que está doente e se a gente não cuidar ela vai morrer (E9).

Esse processo se alinha à compreensão de que o modelo de saúde pública preconizado pelo SUS sofre um processo de fragilização. Desde sua institucionalização, o sistema vem sofrendo influência das tensóes entre o mercado e a cidadania. Por isso, seus fundamentos se apresentam contraditórios com o modo e a relação de produção das sociedades capitalistas. O SUS acaba por se adequar ao sistema hegemônico, afastando-se de seus princípios doutrinários, ou seja, o modelo de saúde hegemônico vai dominando os ideários de saúde trazidos com o Movimento da Reforma Sanitária. Esta reforma, que trazia como proposta inicial a mudança de paradigma por meio da luta política e ideológica contra-hegemônica, foi reduzida à criação de um novo sistema de saúde, sem alterar a estrutura do sistema hegemônico (GOMES; BEZERRA, 2014). 
Há, ainda, a necessidade de fortalecer a região de saúde, o que envolve um entendimento ampliado acerca da política de regionalização. Entre as alternativas para este fortalecimento, foram destacadas a sensibilização dos gestores e sua qualificação técnica:

Existe a necessidade de qualificação técnica dos seus membros, no sentido de também qualificar os processos de discussão de propostas que realmente contemplem as necessidades regionais e não só se configurem como espaços de pactuação meramente cartoriais (E8).

Para além do protagonismo dos municípios, o olhar e o compromisso regional, articulados pelos Estados e suas instâncias regionalizadas, produzem, como já acontece em outras políticas públicas, maior potência e solidariedade aos processos regionais de planejamento e avaliaçáo, fundamentais na organização das redes de atenção à saúde (MENDES; LOUVISON, 2015). Para Viana e Lima (2011, p. 15), é natural que processos assentados em princípios que envolvem a igualdade, a descentralização e a regionalização tendam a ser lentos e negociados. Presumem o entendimento entre autoridades políticas possuidoras de diversos tipos de legitimidade, as quais agregam e empregam diversos recursos. Ou seja, "envolvem jogos de cooperação e competição, acordos, vetos e decisôes conjuntas entre governos que possuem interesses e projetos frequentemente divergentes na disputa política”.

Dessa forma, como um dos desafios no processo de avaliação em saúde no estado do Acre, sugere-se o empoderamento da Comissão Intergestores Regional (CIR), considerada um instrumento frágil e desarticulado, confirmando-a como a instância preconizada legalmente.

Empoderar a CIR para que se torne espaço de negociaçóes e pactuaçóes, legitimando-a como espaço de planejamento, regulação, controle, monitoramento e avaliaçáo regional (E20).

$\mathrm{Na}$ opinião de Santos e Campos (2015), uma região sólida pode unir o que a descentralizaçấo fragmentou. Deve-se considerar, portanto, o papel do gestor municipal enquanto sujeito integrador do sistema de saúde, o qual participa de forma efetiva nos aspectos político, financeiro e técnico. Os autores entendem que a região de saúde deve ser compreendida do ponto de vista da integralidade, e não vista como simples divisão administrativa do Estado. À região cabe resolver a grande maioria das necessidades de saúde da populaçáo regional e integrar um sistema nacional, estadual e intermunicipal. 


\section{Cultura avaliativa e controle social}

Os desafios apontados traduzem a falta de uma cultura avaliativa, considerada um elemento crítico no processo de avaliaçáo em saúde. Há a necessidade de ser estabelecida essa cultura a partir do envolvimento de todos e da mudança de pensamento sobre a importância de se avaliar e monitorar. Os profissionais e os gestores, entendem os entrevistados, devem sair de seus espaços institucionalizados no âmbito dos escritórios e verificar in loco as necessidades das pessoas que vivem o SUS no dia a dia.

Deve haver, portanto, uma visão holística do processo de avaliação em saúde. Reconhece-se que a saúde dos indivíduos e das comunidades também é determinada por influências econômicas, sociais e ambientais e, por isso, torna-se necessário envolver a sociedade no processo de gestáo da saúde e, por outro lado, fazer com que esta perceba o papel protagonista que deve assumir nesse processo.

Eu acho que os gestores têm que ouvir muito, os gestores têm que dar a atençáo merecida aos segmentos organizados da sociedade, sobretudo o conselho, que agrega várias entidades de diversos segmentos [...]. Eu acho que quando começar a se pensar dessa forma e a sociedade entender que tem direito, que tem que questionar, que tem que fazer o controle social e os governos voltarem um olhar que tem que ouvir a sociedade para poder fazer uma execução à altura que a sociedade almeja, com certeza, sim, a gente vai chegar lá (E6).

Além do envolvimento dos usuários, outra questão apontada é a qualificação, não apenas do gestor e do profissional de saúde, mas também da comunidade. Isso se traduz em uma mudança de perfil político por parte da gestáo. A comunidade, nesse caso, deve contribuir para a construção do programa de saúde, pois não é suficiente haver um plano elaborado sem que haja um perfil diagnóstico realizado pela própria comunidade.

Quando você pode trabalhar a prevenção na comunidade, não adianta, tem que fazer um plano de fato, com perfil diagnóstico de fato construído pela própria comunidade (E17).

A gestão social deve ser considerada para que o direito à saúde possa se firmar no que compete à democratização das informaçóes, com a clara expressáo dos julgamentos e tomadas de decisóes sobre os cuidados oferecidos. Para Pinheiro e Silva Junior (2011, p. 39), cabe à gestão pública desenvolver competências avaliativas participativas de forma a potencializar os diferentes atores (gestores públicos, trabalhadores do SUS e usuários) em suas práticas cotidianas, tendo em vista que "nesses arranjos as responsabilidades passam a ser compartilhadas na esfera pública de decisóes”. 
O estímulo à cultura avaliativa traz a necessidade de qualificação dos profissionais de saúde no sentido de estarem aptos para avaliar e para utilizar os resultados da avaliação na rotina de trabalho. Para além disto, os usuários devem ser capazes de identificar os benefícios proporcionados pela avaliação e os gestores em utilizar a avaliação como uma essencial ferramenta de trabalho (OLIVEIRA; REIS, 2016).

Nesse sentido, Takeda e Talbot (2006, p. 569) argumentam que as instituiçôes não podem deixar de exercer a avaliação, entendida como uma responsabilidade. E o que seria institucionalizar a avaliação? Para os autores, seria incorporá-la ao sistema, possibilitando "monitorar a capacidade dos serviços em responder às necessidades em saúde; acompanhar os efeitos das intervençôes; identificar e corrigir problemas; enfim, retroalimentar equipes de saúde, gestores, políticos e comunidades”. E o que seria não avaliar? Os autores comparam a não avaliação a como pilotar um avião sem os instrumentos de navegação aérea, sem indicadores das condiçóes do voo e do motor, ou seja, seria "voar sem bússola, altímetro, velocímetro, indicadores de nível de combustível, óleo e temperatura da água”.

\section{Considerações finais}

A partir dos depoimentos dos sujeitos da pesquisa, evidenciou-se um cenário em que a avaliação em saúde existente é uma exigência imposta pelo Ministério da Saúde e, portanto, um instrumento normativo e cartorial. Há um processo no qual os instrumentos não se articulam. É problemático, visto a avaliação pouco dialogar com os instrumentos de gestáo do governo. É falho, pois considera em "melhor patamar" a média e a alta complexidade, mesmo com as enormes dificuldades e desafios impostos à atenção básica.

Dessa forma, a hipótese mais genérica, consubstanciada a partir da análise das informaçóes relatadas pelos sujeitos da pesquisa, diz respeito à incipiência do processo de institucionalização da avaliação em saúde no âmbito do SUS do estado do Acre. Entretanto, questiona-se se a avaliação poderia vir a se transformar em um elemento que pudesse contribuir efetivamente para a construçáo democrática da política de saúde no SUS do estado.

Ao terem consciência das fragilidades do processo de avaliação em saúde atual, os trabalhadores apontaram alguns desafios para o processo de avaliação. Dentre eles, a melhoria da qualidade da gestão, o foco na avaliação qualitativa e 
na intersetorialidade, o estabelecimento de uma cultura avaliativa e de controle social, o fortalecimento das regiôes de saúde e a utilização da avaliação como um instrumento de fortalecimento do SUS. A avaliação em saúde deve voltar-se para o real problema da população e se desvencilhar de uma lógica aliada ao capital, a qual tende a promover doença ao invés de saúde.

A contribuição deste artigo, desse modo, é no sentido de questionar o atual processo de avaliação em saúde no âmbito do SUS do estado do Acre. Espera-se que este estudo incentive o debate sobre a avaliação enquanto um instrumento que favorece a participação, sua adaptabilidade aos cenários locais e reforce o debate e o desenvolvimento de políticas públicas, fazendo contraposição aos interesses hegemônicos no momento em que se torna um elemento para democratizar as instituiçôes de saúde pública. ${ }^{4}$

\section{Referências}

ACRE (Estado). Secretaria de Estado de Saúde. Plano Estadual de Saúde (2016-2019). Rio Branco: Sesacre, 2016.

Secretaria de Estado de Saúde. Plano Estadual de Saúde (2012-2015). Rio Branco: Sesacre, 2012.

ALMEIDA, C. A. L. de. TANAKA, O. Y. Avaliação em saúde: metodologia participativa e envolvimento de gestores municipais. Rev. Saúde Pública. São Paulo, v. 50, n. 45, p. 1-10, 2016. ATKINSON, R.; FLINT, J. Accessing Hidden and Hard-to-Reach Populations: Snowball Research Strategies. Social Research Update. v. 33, n. 1, p. 1-4, 2001.

BARDIN, L. Análise de conteúdo. São Paulo: Ediçōes 70, 2011.

CARNUT, L. Theorizing about Performance Evaluation of Health Systems from the Perspective of Civil Society. Open Journal of Social Sciences. China, v. 8, p. 394-411, 2020.

CASTEL, R. El ascenso de las incertidumbres: trabajo, protecciones, estatuto del indivíduo. Buenos Aires: Fondo de Cultura Económica, 2010.

CONTANDRIOPOULOS, A.-P. et al. A avaliação na área da saúde: Conceitos e métodos. In: HARTZ, Z. M. de A. (Org.). Avaliação em Saúde: dos modelos conceituais à prática na análise da implantaçáo de programas. Rio de Janeiro: Ed. Fiocruz, 1997, p. 29-48.

CRUZ, M. M. Avaliação de políticas e programas de saúde: contribuiçôes para o debate. In: MATTOS, R. A.; BAPTISTA, T. W. de F. Caminhos para análise das politicas de saúde. Porto Alegre: Rede Unida, 2015, p. 284-317. 
DUARTE, R. Pesquisa qualitativa: reflexões sobre o trabalho de campo. Cadernos de Pesquisa. São Paulo, n. 115, p. 139-154, 2002.

FELISBERTO, E. et al. Institucionalizando a avaliação nas organizaçóes e agências de pesquisas: um estudo de caso exemplar. Saúde Debate. Rio de Janeiro, v. 41, n. esp., p.387-399, 2017.

FURTADO, J. P. et al. Planejamento e Avaliação em Saúde: entre antagonismo e colaboração. Cad. Saúde Pública. Rio de Janeiro, v. 34, n. 7, p. 1-12, 2018.

GASPARINI, M. F. V.; FURTADO, J. P. Avaliação de Programas e Serviços Sociais no Brasil: uma análise das práticas no contexto atual. Serviço Social \& Sociedade. São Paulo, n. 117, p. 122-141, 2014.

GOMES, W. da S.; BEZERRA, A. F. Benjamin. Programa de melhoria do acesso e qualidade da atenção básica: reflexóes sobre o papel da avaliação na efetivação da integralidade em saúde. Saarbrucken, Deutschland: Novas Ediçóes Acadêmicas, 2014.

KUMAR, M.; MOSTAFA, J.; RAMASWAMY, R. Federated health information architecture: Enabling healthcare providers and policymakers to use data for decision-making. Health Information Management Journal. Australia, v. 47, n. 2, p. 85-93, 2018.

MARTINS, P. H.; BEZERRA, R. Gestão pública local em saúde na perspectiva do duplo registro: contribuições das teorias de Goffman e Mauss. In: MARTINS, P. H. et al. Produtivismo na saúde: desafios do SUS na invenção da gestão democrática. Recife: Ed. Universitária da UFPE, 2014, p. 27-52.

MARTINS, P. H. Repensando sociologicamente a noção linear de determinantes sociais. In: PINHEIRO, R.; MARTINS, P. H. N. (Org.). Avaliação em saúde na perspectiva do usuário: abordagem multicêntrica. Rio de Janeiro: CEPESC/IMS-UERJ; Recife: Editora Universitária UFPE; São Paulo: Abrasco, 2011, p. 53-60.

MARTUCCELLI, D. Crítica da Filosofia da Avaliação. In: BALANDIER, G. (Org.). O que avaliar quer dizer? São Paulo: Editora Fap-Unifesp, 2015, p. 37-63.

MENDES, A.; LOUVISON, M. O debate da regionalizaçáo em tempos de turbulência no SUS. Saúde e Sociedade. São Paulo, v. 24, n. 2, p. 393-402, 2015.

MÉSZÁROS, I. O poder da ideologia. Trad: Magda Lopes e Paulo Cezar Castanheira. São Paulo: Boitempo, 2012.

MIRANDA, A. S. de; CARVALHO, A. L. B. de; CAVALCANTE, C. G. C. S. Subsídios sobre práticas de monitoramento e avaliação sobre gestão governamental em Secretarias Municipais de Saúde. Ciência \& Saúde Coletiva. Rio de Janeiro, v. 17, n. 4, p. 913-920, 2012.

OLIVEIRA, A. E. F. de; REIS, R. S. Gestão pública em saúde: os desafios da avaliação em saúde. São Luís: Edufma, 2016. 
PINHEIRO, R.; SILVA JUNIOR, A. G. da. A centralidade do usuário na avaliação em saúde: outras abordagens. In: PINHEIRO, R.; MARTINS, P. H. N. (Org.). Avaliação em saúde na perspectiva do usuário: abordagem multicêntrica. Rio de Janeiro: CEPESC/IMS-UERJ; Recife: Editora Universitária UFPE; São Paulo: Abrasco, 2011, p. 37-52.

PISCO, L. A. A avaliação como instrumento de mudança. Ciência \& Saúde Coletiva. Rio de Janeiro, v. 11, n. 3, p. 564-576, 2006.

ROSEBOOM, K. J. et al. Economic evaluations of health technologies in Dutch healthcare decisionmaking: a qualitative study of the current and potential use, barriers, and facilitators. BMC Health Services Research. United Kingdom, 2017.

SANTOS, L.; CAMPOS, G. W. de S. SUS Brasil: a região de saúde como caminho. Saúde e Sociedade. São Paulo, v. 24, n. 2, p. 438-446, 2015.

SILVA, L. M. V. da; FORMIGLI, V. L. A. Avaliação em saúde: limites e perspectivas. Cadernos de Saúde Pública. Rio de Janeiro, v. 10, n. 1, p. 80-91, 1994.

TAKEDA, S.; TALBOT, Y. Avaliar, uma responsabilidade. Ciência \& Saúde Coletiva. Rio de Janeiro, v. 11 n. 3, p. 564-576, 2006.

TAMAKI, E. M. et al. Metodologia de construçáo de um painel de indicadores para o monitoramento e a avaliação da gestão do SUS. Ciência \& Saúde Coletiva. Rio de Janeiro, v. 17, n. 4, p. 839-849, 2012.

TANAKA, O. Y. Avaliação em Saúde: novos tempos, novas construçóes. In: TANAKA, O. Y.; RIBEIRO, E. L.; ALMEIDA, C. A. L. (Org.). Avaliação em Saúde: contribuiçôes para incorporação no cotidiano. Rio de Janeiro: Atheneu, 2017.

VIANA, A. L. d’Á.; LIMA, L. D. de. O processo de regionalização na saúde: contextos, condicionantes e papel das Comissóes Intergestores Bipartites. In: (Org.). Regionalização e relaçôes federativas na política de saúde do Brasil. Rio de Janeiro: ContraCapa, 2011, p. 11-24.

\section{Notas}

${ }^{1}$ No estado do Acre há três regiōes de saúde: "Baixo Acre e Purus", "Alto Acre” e "Juruá, Tarauacál Envira”.

${ }^{2}$ Plano de Governo, Plano Plurianual (PPA), Lei de Diretrizes Orçamentárias (LDO) e Lei Orçamentária Anual (LOA).

${ }^{3}$ Plano de Saúde, Programação Anual em Saúde e Mapa da Saúde.

${ }^{4}$ L. M. Teston, A. Mendes, L. Carnut e M. Louvison contribuíram igualmente para a concepção, o planejamento, a análise e a interpretação dos dados; na elaboração e revisão crítica do conteúdo; e na aprovação da versão final do manuscrito. Este artigo decorre de parte de tese com bolsa concedida pela Coordenação de Aperfeiçoamento de Pessoal de Nível Superior (Capes). 


\section{Abstract}

Challenges of health evaluation in the SUS from the viewpoint of health workers in the State of Acre, Brazil

The evaluation permeates the field of public health. It makes it possible to obtain information aimed at the construction of judgments capable of being translated into actions related not only to the improvement of public policies, but also to the assistance of social groups in understanding and modifying their problems. This article aims to know the perceptions of SUS workers about the health evaluation process carried out in Acre and, from these perceptions, reflect on the limits and challenges of doing health evaluation in the state. For this, 26 semi-structured interviews were carried out with SUS workers, as well as with users and managers who are members of the State Health Council. The testimonies were submitted to the content analysis technique. Health assessment is perceived as a powerful management tool, however, little used in the daily life of managers. Problems related to articulation, planning and management contribute to a process of evaluation considered incipient and cartorial. Qualitative evaluation, intersectoriality, evaluative culture and social control are some of the challenges pointed out. There is a need for health assessment to constitute a social practice, not limited to compliance with rules and norms.

> Keywords: Unified Health System. Health Policy. Health Assessment. Health Personnel. 